\title{
المهارات الاجتماعية وعلاقتها بتقبل طفل الروضة للاخر
}

إعداد

الباحثة / ليلى رشدى مصطفى '

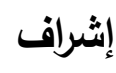

أ ـد . عفاف أحمد عويس

أستاذ علم النفس

كلية التربية للطفولة المبكرة

جامعة القاهرة
أ.د. سهير كامل احمد

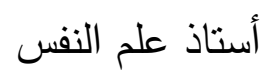

والعميد الاسبق لكلية التربية للطفولة المبكرة

جامعة القاهرة

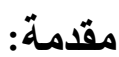

تعد مرحلة الطفولة من أهم المراحل في حياة الانسان فهي مرحلة التكوين ونمو الثخصبة، والتي تتطلب أثنكالا من الرعاية والحماية الاجتماعية، وتعتبر المهارات الاجتماعية من المهارات ذات الاهمية في حياة الإنسان منذ طفولته حيث هي التي تساعد علي أن يتحرك نحو الآخرين فيتفاعل، ويتعاون معهم ويشاركهم ما يقومون بـه من أنشطة، ومهام، وأعمال مختلفة، ويتخذ منهم الاصدقاء، ويقيم معهم العلاقاتهوينشأ بينهم الاخذ والعطاء فيصبح عضوا فعالا في جماعته يؤثر في الآخرين، ويتأثر بهه، ويعبر عن مشاعره، وانفعالاته واتجاهاته نحوهم.بات من المؤكد والضروري أن نشر نقافة التسامح والتعايش وقبول الآخر المختلف حاجة أساسية وملحة يجب زرعها في نفوس وعقول الجيل الناشئ، لأنها تساهم بشكل فعال في خلق جيل واع قادر على تحمل أعباء المسؤولية وقيادة المرحلة القادمة بشكل ايجابي. 
ولا يتحقق التسامح وقبول الآخر ، إلا بالحوار والتواصل، والمشاركة الحقيقية في اتخاذ القرار، لأن إقامة حوار

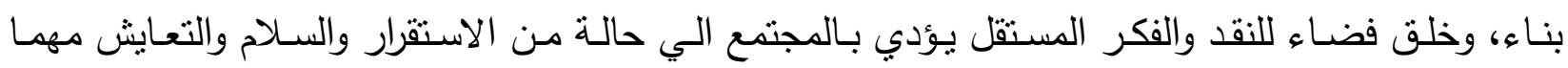
اختلفت أعراق ومعتقدات أبنائه.

وتري الباحثة ضرورة الاهتمام بالمهارات الاجتماعية، وتزويد كل طفل بها، كي يستطيع مواجهة التحديات العصرية، والتعامل مع الآخرين، وتحقيق التكيف والتوافق مع بيئته ومجتمعه.

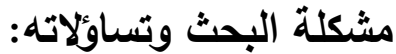

وتري الباحثة ان الآخر بالنسبة للطفل اصبح اكثر تعقيدا وتتوعا حيث اتسع الكون من حوله واصبح من

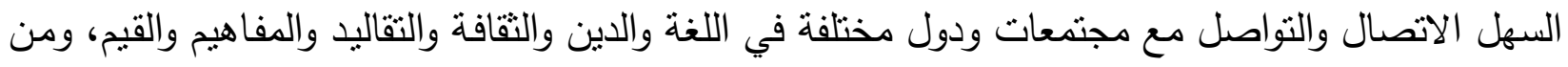

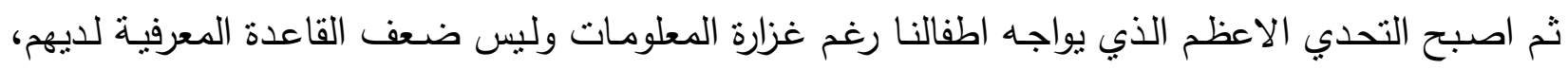

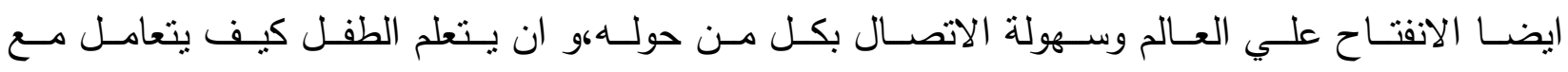
الآخر (يشارك،يتعاون، يساعد) وكيف يكون مسئولا بجانب ذلك عن نفسه، وكيف يتعامل مع الافكار الجديدة،

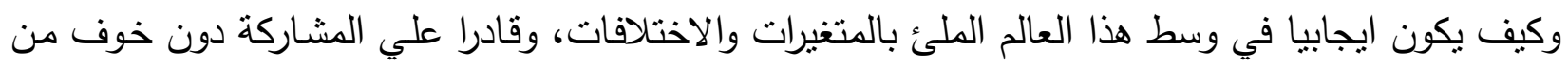

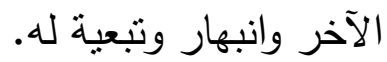

وان ادراك الآخر يخضع لعمليات أهمها التتشئة الاجتماعية واللغة والتفاعل الاجتماعي والخبرات الثخصية المكتسبة والمعانشة والقدوة التي مر بها الفرد وكل هذه العوامل والعمليات تتكل ادرالك الآخر وتكوين صورة

ذهنية أكثر ما يميزها أنها ذات طابع انفعالي وجداني وبالثالي تحديد اساليب التعامل معه. ويمكن بلورة المشكلة في التساؤل الرئيس التالي:

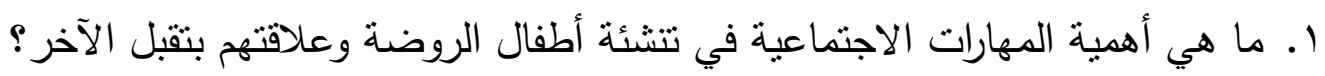

r. ما هي المهارات الاجتماعية المناسبة لطفل الروضة؟ هئ لهاته أهداف البحث: يهدف البحث الحالي الي: ا ـ معرفة العلاقة بين المهارات الاجتماعية وتقبل طفل الروضة للاخر .

r. تحديد المهارات الاجتماعية المناسبة لطفل الروضة؟ لئج أهمية البحث: بيتمد البحث الراهن أهميته من النقاط التالية: 
1. أهمية الموضوع التي تتصدي لـه الباحثة حيث تسعي الي معرفة تأثنير المهارات الاجتماعية التي يكتسبها طفل الروضة علي علاقته بالآخر المختلف عنه في(الجنس، العقيدة، المستوي الاقتصادي).

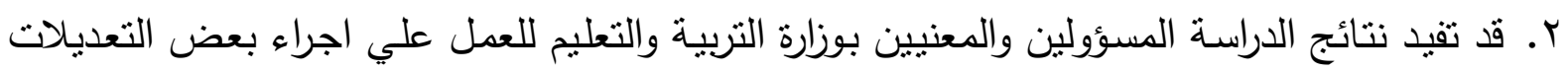

اللازمة منهج رياض الاطفال المعني بتتمية ثقافة قبول الآخر .

مصطات البحث:

Social Skills المهارات الاجتماعية

تعرف الباحثة المهارات الاجتماعيـة اجرائيـا بأنها "مجموعـة مـن الخبرات والانشطة التي يكتسبها طفل فئل

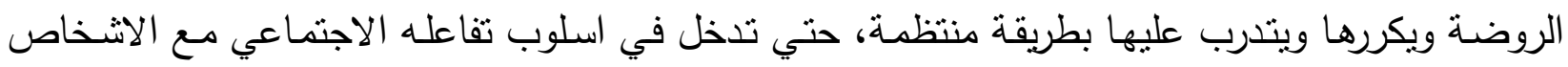
والاثشياء من حوله ويؤدي ذللك الي مساعدنه علي التكيف مع المجتمع" بطريه

\section{تقبل الآخر Acceptance of the other:}

تعرف الباحثة تقبل الآخر اجرائيا علي أنه: " تقبل الفرد لافكار وأراء واتجاهـات غيره من النـاس الذين يختلفون عنه في النوع والعقيدة والمستوي الاقتصادي والاجتماعي والنواصل الايجابي معهم واستدعاء الصور الذهنية الايجابية عنهم ونوقع الافضل في علاقته معهم".

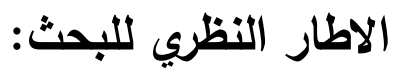

تعتبر المهارات الاجتماعيـة هي الاسـاس في بنـاء شخصية الطفل وقبوله كعضو فعال في المجتهع في المستقبل، وهذه المهارات توضع أساسها في مرحلة الطفولة المبكرة ويكتسب الطفل من اسرته وبيئته عادات مجتمعه وتقاليده، فمشاركة الطفل لاسرته ومجتمعه سواء في احتفالاته بأعياده وطقوسه وكذلك مراقبته للادوار الاجتماعية سواء داخل الاسرة او في محيط المجتمع، وكل هذا يجعله يمتصمقومات شخصيته من مجتمعه، لذلك اذا استطاع الطفل اكتساب تلك المهارات وممارساتها في مجتمعه بصورة سليمة وايجابية فأن شخصيته تتمو بصورة سوية. 


\section{أولا:-المهارات الاجتماعية لطقل الروضة: \\ مفهوم المهارات الاجتماعية:}

تناول العديد من الباحثين مفهوم المهارات الاجتماعية من عدة جوانب مختلفة ونعرض فيما يلي وجهة نظر الباحثين حول مفهوم المهارات الاجتماعية. تعرفها سهير شاش( ( . . r) بأنها قدرة الطفل علي التفاعل الاجنماعي مع الاقران، والاستقلال والتعاون مـع الآخرين والقدرة علي ضبط الذات، الي جانب نوافر المهارات الثخصية في اقامة علاقات ايجابية بناءة.

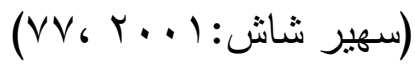

كم عرفها ايمن المحمي( ( . ب)( بأنها عبارة عن مجموعة السلوكيات اللفظية وغير اللفظية التي يتعلمها

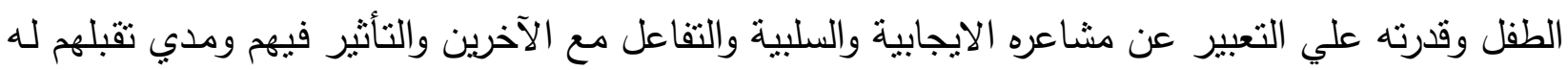
والضبط الانفعالي والاجتماعي أثناء المواقف الاجتماعية.

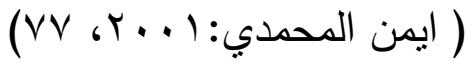

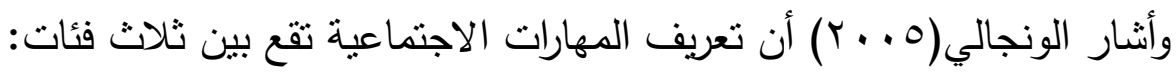
أ- - تعريفات ركزت علي قبول الاصدقاء. ب- تعريفات ركزت علي الجانب السلوكي في تعريف المهارات الاجتماعية.

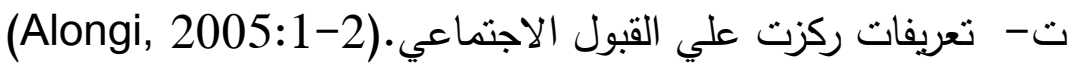

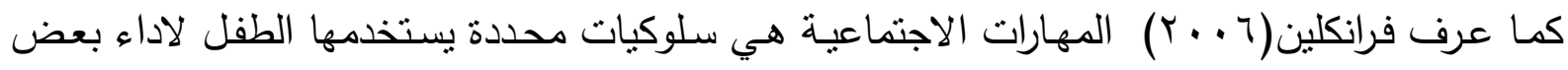
المهام الاجتماعية بكفاءة ونجاح منل بدء الحوار ، تقديم مجاملة، واللعب علي نحو مستمر مع مجموعة. (Franklin, 2006: 75)

ويضيف (Eckert, 2002) أن المهارة الاجتماعية لابد أن يكون لها منفعة للثخص أو للاخرين أو تكون

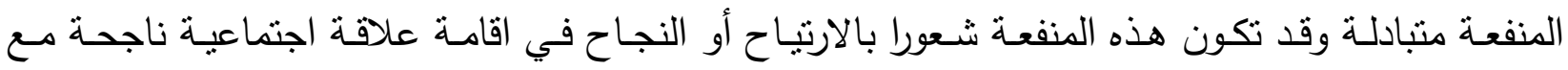
الآخرين منل تكوين صداقة، أو زيادة تفاعل الفرد مع أقرانه، أو سرور نابع من انجاز أعمال جماعية.

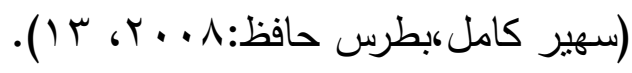

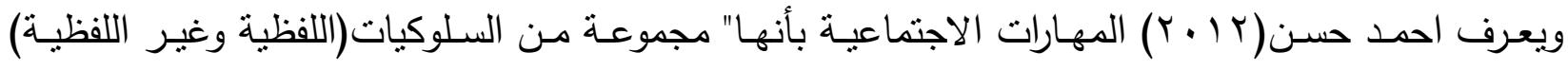
المكتسبة والتي تمكن الفرد من التفاعل في المواقف المختلفة بطريقة ملائمة وفعالة والتي تنؤدي الي نتائج

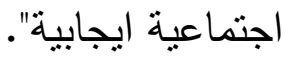

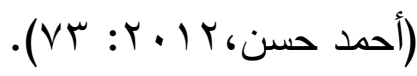




$$
\begin{aligned}
& \text { تصنيف العلماء والباحثين لانواع المهارات الاجتماعية: }
\end{aligned}
$$

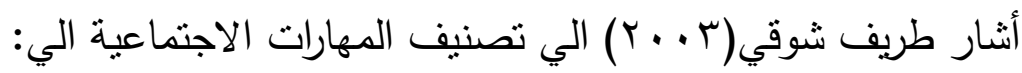

$$
\begin{aligned}
& \text { أ- مهارات نوكيد الذات } \\
& \text { ج- مهارات اتصالية: وتتقسم بدورها الي قسمين: }
\end{aligned}
$$

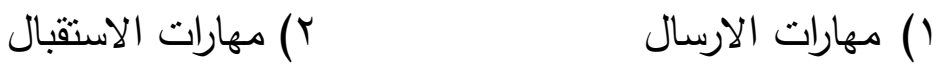

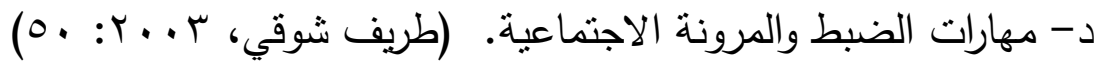

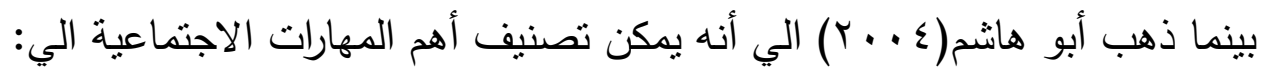

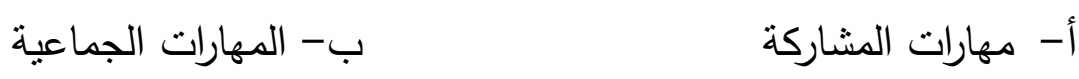

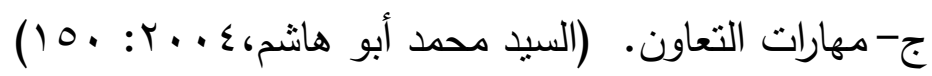

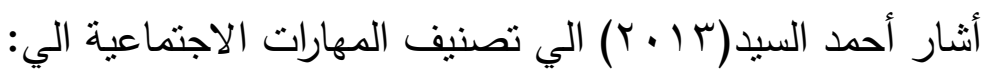

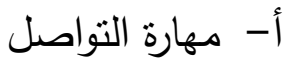

ويقصد بها قدرة الطفل علي علي التواصل لفظيا أو غير لفظيا مع الاطفال الاخرين

$$
\text { ب- مهارة المشاركة والتعاون }
$$

ويقصد بها قدرة الطفل علي اقامسة علاقات وثثقة ووديـة مـع الاخرين، والتعاون معهم علي نحو

يساعده علي الاقتراب منهم، والتقرب اليهم، ليصبح أكثر قبولا لديهم.

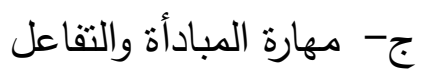

ويقصد بها قدرة الطفل علي المبادرة بالحوار من جانبه مع الاطفال الاخرين.

\section{مجالات المهارات الاجتماعية لطقل الروضة:}

تتتوع مجالات المهارات الاجتماعية وتتفرع ، وقد قسمها العلماء المهتمون بهذا المجال حسب عدة اتجاهات منها:

اتجاه يهتم بهذه المهارة من حيث امكانية تتميتها في مجال التعلم والدراسة وحصرها في الاتي:قيادة

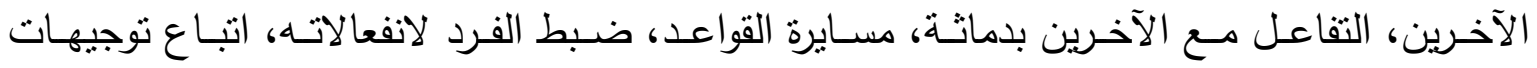

الآخرين، اتخاذ القرار، التصرف بمسئولية ابي يكون الفرد مسئولا عن انفعاله، مساعدة الآخرين

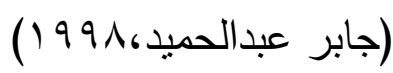

وحددها اتجاه اخر حسب اهميتها بالنسبة للعمر الزمني الذي يمر بـه الانسـان وجاءت في تقدير

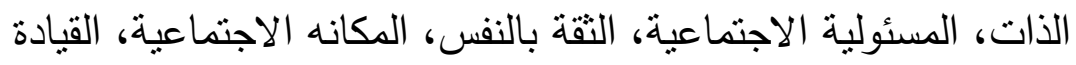

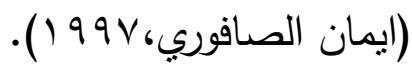


في حين قسمت في مجال اخر حسب مهارة الفرد في ارسال وفهم وتفسير المعلومات الاجتماعية أي مهارة المشاركة الاجتاعية مثل: التعبير اللفظي والانفعالي، مشروعية السلوك الاجتماعي، القدرة علي

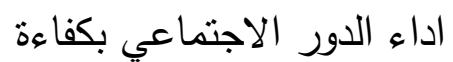

(Riggio R E.,1999)

• وهناك العديد من الدراسـات التي اهتمت بتحديد هذه المجالات في مهارات الاعتمـاد علي النفس والاستقلالية، والمبادأه ومهارات التعاون، وضبط النفس.

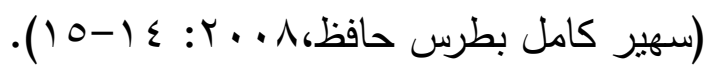

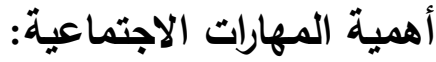

ترجع أهميـة المهارات الاجتماعية الي قدرتها علي مسـاعدة الطفل في تكوين علاقات اجتماعيـة سوية مـع

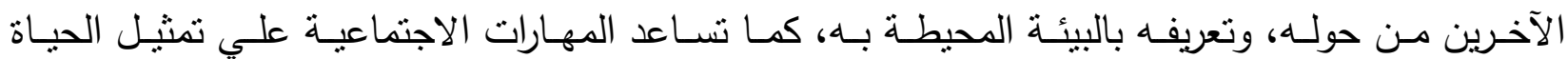

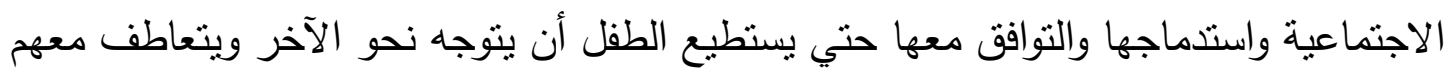

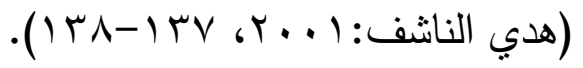

ويمكن ايجاز أهمية المهارات الاجتماعية في النقاط التالية: تعتبر المهارات الاجتماعية عاملا مهما في تحقيق التكيف الاجتماعي لدي الاطفال داخل الجماعات التي ينتمون اليها وكذلك المجتمع ويساعدهم أيضا علي التفاعل مع الرفاق والابتكار والابداع في حدود طاقاتهم الذهنية والجسدية. كما يساعدهم علي اكتساب التقة في النفس ومشاركة الآخرين في الاعمال التي تتفق وامكانياتهر

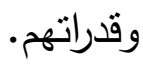

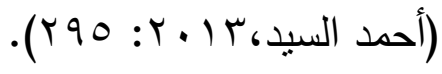

تقفيد المهارات الاجتماعية الاطفال في التغلب علي مشكلاتهم وتوجيه تفاعلهم مع البيئة الدحيطة. المهارات الاجتماعية تجعل التعامل مـع الاخرين فعالا تجعل الانسان قادرا علي مواجهة الاخرين

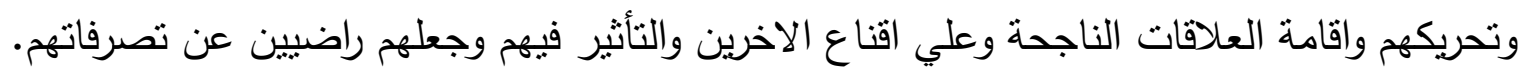

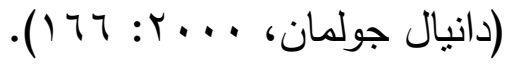




\section{ثانيا: تقبل طقل الروضة للاخر:}

تقبل الآخر عملية تربوية بالدرجة الاولي، ذلك لان الانسان كائن اجتماعي بطبعه، وسلوكياته متعلمة، لذا

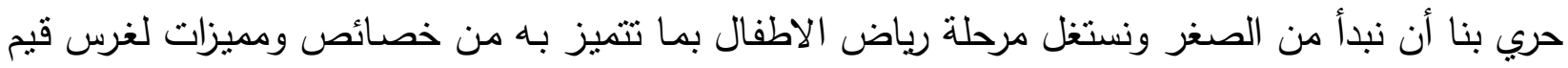
ومبادئ تقبل الآخر أملا في جني ثمار ذلك في الاجيال الصاعدة. فتقبل الآخر هو سلوك متعلم يتربي عليه الفرد من قبل المؤسسات التربوية، والتي تساهم في انتاجه الي لي لهي المجتمع، سواء العائلة الصغيرة من الام والاب، من خلال كيف تربي ابنائها، وما هي الاساليب التي تعتمد عليها في التربية، بالاضافة الي دور المؤسسات التربوية الآخري كرياض الاطفال، والمدارس، والمؤسسات الدينية، والاجتماعية، والثقافية والاحزاب السياسية، والتي تساهم في تشكيل شخصية الفرد، ولها دور كبير في تربية مفهوم وثقافة تقبل الآخر • ت

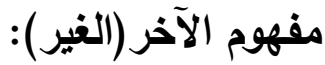$$
\text { الآخر عند (العارف باله، r... إ) نوعان: }
$$

ا. الآخر المعلوم: المعرفة به جاءت من أحد سبيلين، اما المعايشـة الفعلية معه أو الاستماع، والمعرفة به عن بعد دون ان تتاح امكانية الاتصال به، وهذا المنحني الاخير في تشكيل صورة الآخر قد تلعب فيـه الادراكات والتصسورات ومضمون التفكير وسمات الثخصية دورا كبيرا في بلورته ووضعه في صورة اطار . - مار r. الآخر المجهول: فتكوين صورته يعتمد علي البناء المعرفي والنفسي للفرد وفقا للمعلومات الجزئية، وعوامل الجنب والتشويق أو النفور •

يقترن مفهوم الآخر بمفهوم الغيريـة أو الغير، ويرجع اختلاف التتاول لكل من المصطلحين الي اختلاف التبعيـة الثقافيـة، ففي المغرب العربي يستخدمون مصطلح الغير تأثثرا بمعظم الكتابـات الوجوديـة الفرنسية والالمانية، اما المفكرون المصريون والثاميون فيميلون لاستخدام مصطلح الآخر .

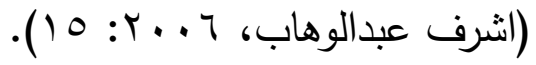


ويذكر أحمد الجهيني، محمد مصطفي" أن تحديد الآخر يتحدد بوجه الاختلاف الذي يفرق بين الانا وهذا الآخر .. فأذا كان البعض يحددون الآخر علي اساس عرقي أو جنسي، فأن هناك من يحدده علي أسـاس لغوي أو عقائدي

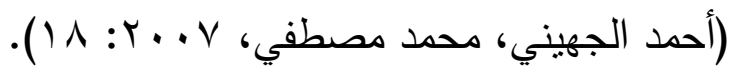

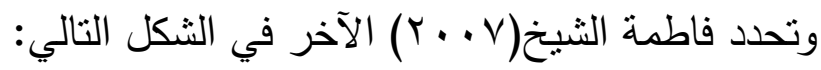

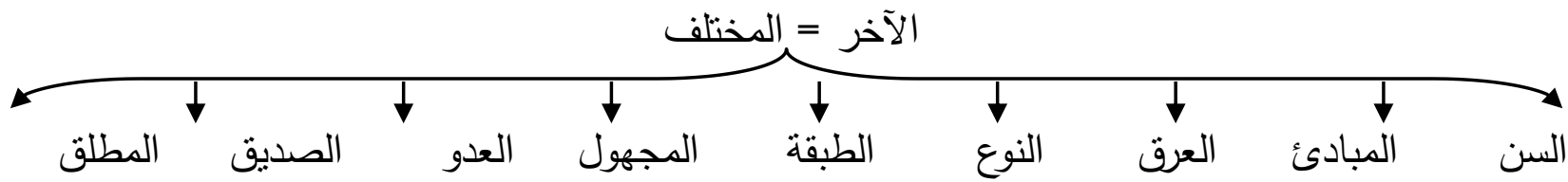
حاكم ومحكوم غني وفقير

ممـا سبق يمكن القول بـان معرفـة الآخروتقبله هي الوجـه المكمل لمعرفة الذات وتقبله، لذا وجب علي المسئولين عن تربية الطفل(الاسرة، المؤسسة التعليمية) أن يعملوا علي ان يتعرف الطفل علي ذوات الآخرين كما يتعرف علي ذاته، وان يتقبل ذوات الآخرين كما يتقبل ذاته.

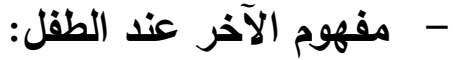

ان مفهوم الآخر ينمو مع الطفل، ويتخذ في كل مرحلة من مراحل النمو شكلا مختلفا حسب منطلبات كل مرحلة، وحسب حاجات الطفل النفسية والاجتماعية، ويأتي النمو العقلي ليشكل الصورة الذهنية للاخر ؛ ليحدد مرد الية التعامل من خلال ثنائية(ذات- اخر ). ومعرفة الآخر هي اثراء للذات بالدرجة الاولي وتعرف عليها، حيث ان معرفة الآخر تؤدي الي بيان مكامن

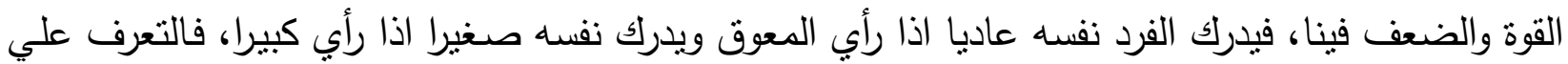
الآخر هو "بلورة لخصائص الذات". وان علاقة الذات والآخر بكل ما تحمله من تفاعلات مستمرة، تعتمد بشكل اساسي علي عدة عمليات اهمها العمليات المعرفية، خاصـة عملية "التصنيف المعرفي والاجتماعي" وقد اعتبرت هذه العملية المسئولة عن ظهور التعصب والقوالب النمطية الجامدة

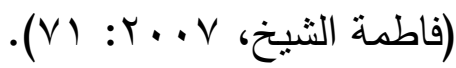




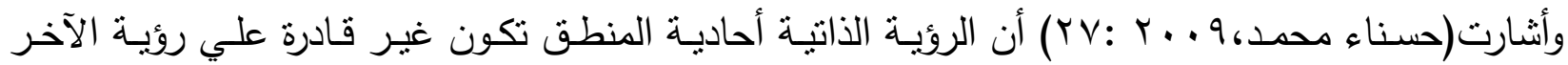
المختلف عن الذات أو الذوات نفسها، والروئة المتألفة الذوات الناتجة عن التفاعل الحر والمتساوي هي وحدهاء

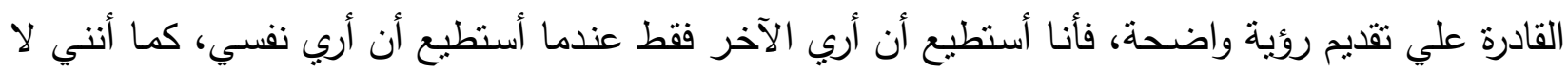
أستطيع أن أري نفسي الا عندما يراني الآخر ، والنظرة التي أنظر بها الي الآخر يجب أنس أن تكون قادرة أيضا علي استقبال روئة الآخر لي. وبالنسبة للطفل فتشكل صورة الآخر لديه يتم من خلال رصد الطفل ومعايشته لممارسة الكبار لانتماءاتهم

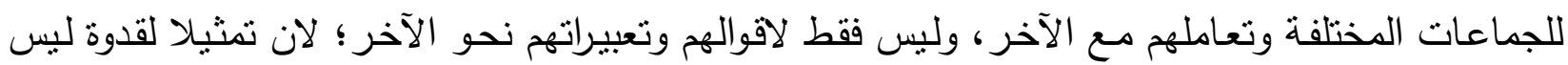
تمثنيا للاقوال بل للممارسة

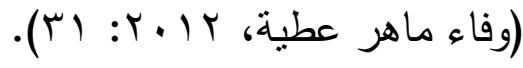

وكذلك يميل الطفل بطبيعته الي تصنيف الاشباء ضمن بعد واحد الا انه يحقق تقدما معرفيا في عمليـة التصنيف ما بين الخامسة والسابعة من العمر اذ ينتقل من التصنيف علي اساس البعد الواحد الي التصنيف علي اساس اكثر من بعد، فنر الطفل اذا اعطيت له مجموعة من الاشكال بعضها منتابهة في الثنكل والآخر متثابه في اللون، اذا صنفها حسب اللون، يعاود بعد ذللك النظر ويصنفها حسب التشابه

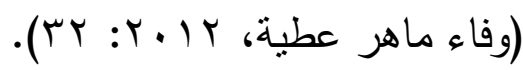

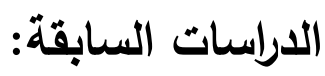

توجد بعض الدراسات التي اهتمت بالمهارات الاجتماعية لاطفال ما قبل المدرسة وعلاقتها بتقبل الطفل للاخر وما يرتبط بها من مفاهيم ذات صلة، وفيما يلي اهم تللك الدراسات وثيقة الصلة بمجال الدراسة الحالية:

هدفت دراسة جريزينكو (Grizenko,2000) الي تقيم احد البرامج التنريبية علي المهارات الاجتماعية والتي تشـمل مفهوم منظور الذات والآخر وشـارك في الدراسـة جس طفـلا من اطفال مـا قبل المدرسة،واستخدمت الدراسـة مقياس المهارات الاجتماعيـةومقياس منظور الذات والآخر ،وكثفت نتائج الدراسـة عن تحسن بعيد المدي في تتمية المهارات الاجتماعية والسلوك تجاه الآخر لدي اطفال المجموعة التجريبية مقارنة بالضابطة. أوضحت دراسة سكولتز (Schultz, 2011) التي تهدف الي التعرف علي تأثير المهارات الاجتماعية علي سلوك اطفال ما قبل المدرسة وركز البرنامج علي تواصل الاطفال مع الآخرين ، واستخدمت الدراسة مقياس التواصل الاجتمـاعي الانفعالي للاطفال، ومقياس تقدير التواصل مـع الآخرين. واسفرت نتائج الدراسـة عن 
تحسن مهارات التواصل مـع الآخرين بعد برنـامج المهارات الاجتماعية، وان الكفاءة الانفعالية الاجتماعيـة بالتغيير الايجابي في سلوك الاطفال.

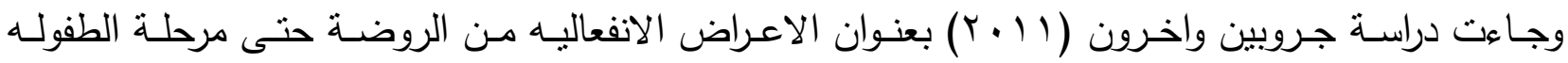

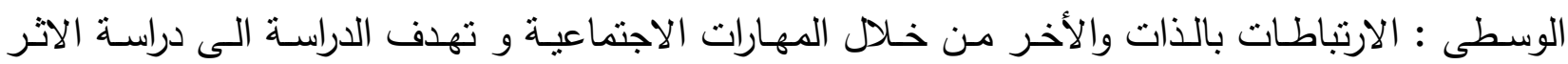
التفاعلى للابعاد المختلفة للمهارات الاجتماعية على الاعراض الانفعاليه لاى الاطفال من خلال التقريق بين المهارات الاجتماعية المتمركزة حول الذات بمعنى التى تركز على الاهداف والاحتياجات الفردية فى التفاعلات الاجتماعية متل التوكيدية والمشاركة الاجتماعية والمهارات الاجتماعية المتمركزة حول الاخر بمعنى التى تركز

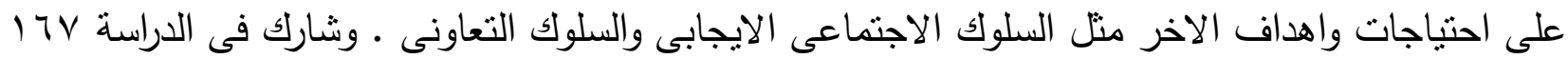
طفل عمر 0، 7، 9 سنوات وتم تقديم مقاييس للوالدين والمعلم والطفل لقياس المرض النفسى لدى الاطفال وقام المعلمين بتقدير المهارات الاجتماعيـة لدى الأطفال ـ وكثفت الدراسـة عن اهميه التحقق من قصـور المهارات الاجتماعية المتمركزة حول الذات لنمو الاعراض الانفعاليه وان انخفاض مستوى التوكيدية ينبئ عن اضطرابات انفعاليه فيما بعد وانه بالنسبة للاطفال منخفضى مستوى السلوك الاجتماعى الايجابى فان زيادة

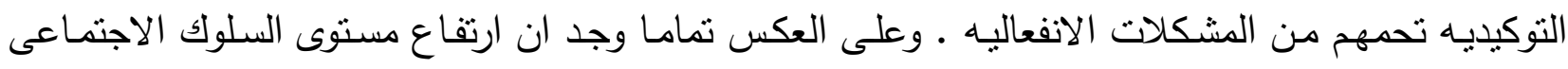
الايجابى يعد عامل خطورة لتطور المشكلات الانفعاليه خاصـة اذا كان مصحوب بانخفاض فى مستويات

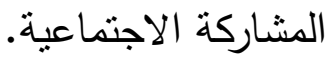

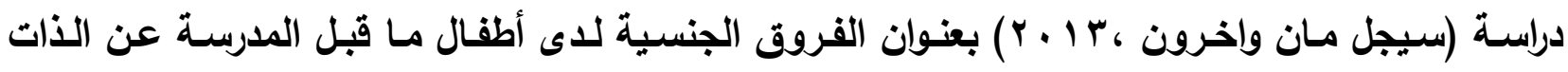
والاخر والتي هدفت الى دراسة الفروق الجنسية عن الذات والاخر فى سياق الجنس من نفس النوع والجنس

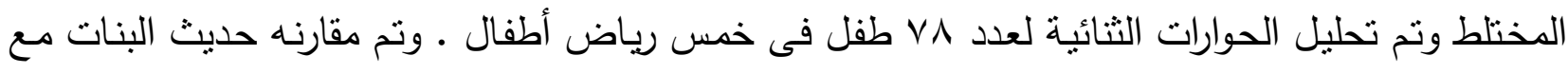
البنات والاولاد مـع الاولاد والتى وجد انها حققت اعلى مستويات الحوار وخاصـة فى التأويل السلبى للأخر وكانت اقل إظهارا للتشابه بين الذات والاخر ـ ولم تلاحظ الدراسة وجود فروق فى السياق مختلط الجنس . وبالمقارنه بين البنات والأولاد فى حديثه معا وجد ان البنات اكثر تحدثا وخاصة فى التشابه والقدرات ـ وعند مقارنه البنات مع البنات والبنات مع الأولاد وجد ان البنات مع الأولاد بطريقة وصفيه او يتحدثون عن الانشطة

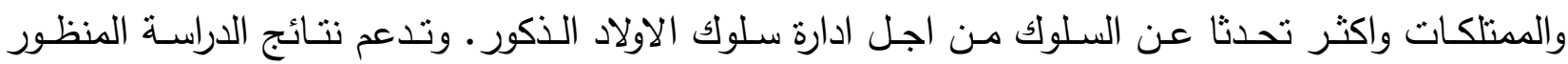
الاجتماعى بنائى او السياقى وليس المنظور البيولوجى عن الفروق الجنسية بين الأطفال .

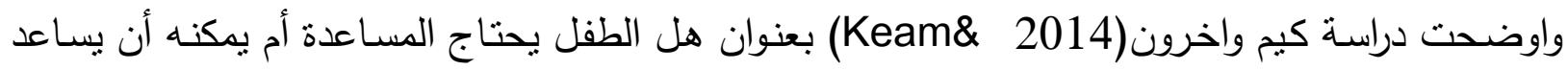
نفسه ؟ توقعات أطفال ما قبل المدرسة عن المساعدة الوسيلية من الأخر مقابل المساعدة الذاتيه 
هدفت الدراسـة الـى دراسـة نوقعـات الأطفـال عن المسـاعدة مـن الذات والمسـاعدة مـن الأخـر وشـارك فى الدراسة( (0) من الأطفال عمر ثلاث سنوات ونصف الى اربع سنوات ونصف ومجموعة عمر خمس سنوات ونصف . وطلب من الأطفال استكمال أحد القصص التى فثل فيها الثخص فى استكمال هدفه (لان مكان الثئ تم تحديده بشكل خاطئ أو كان أعلى من قدرات الثخص) ويقوم شخص اخر بملاحظة الحدث وسال الاطفال عن ما اذا كانوا يتوقعون من الثخص الاخر ان يساعد البطل او يتوقعوا ان يساعد البطل نفسة . وكثفت النتائج ان الاطفال عمر r, ب عام يتوقعون أن الأخر سوف يقدم المساعدة فى معظم المحاولات الفاثـلة للبطل وعلى العكس تمامـا وجد ان الأطفال الأكبر سنا يتوقعون ان الثخص الاخر سوف يسـاعد البطل أو ان البطل قد يساعد نفسة بدرجة منتـابهه . . وكثفت نتائج الدراسة أن هناك انخفاض في المهارات المتمركزة علي الآخر ، وان هناك علاقة بين المهارات الاجتماعية والاعراض الانفعالية وان انخفاض التوكيدية والسلوك الاجتماعي برتبط بالمشكلات الانفعالية. وتري الباحثة أن الاهتمام بالمهارات الاجتماعية لطفل الروضة يتم من خلال الاهتمام باعداد البرامج التربوية الهادفة الغنية بالمثيرات والخبرات والمعارف والانشطة ، وذلك بأسلوب يتتاسب مع اهتمامتهر وحاجاتهم، مما يؤدي الي تقبلهم لذا تهم وتقبلهم للاخرين بشكل ايجابي وفعال.

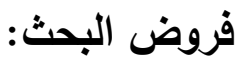
ا-لا توجد فروق ذات دلالـة احصـائية في المهارات الاجتماعيـة علي مقياس المهارات الاجتماعيـة لدي أطفال الروضة. ץ- لا توجد فروق ذات دلالـة احصائية في التقبل للاخر علي مقياس قبول الاخر المصور لدي أطفال الروضة. ז- توجد علاقة موجبة ذات دلالة احصائية بين المهارات الاجتماعية وتقبل الاخر لدي أطفال الروضة. 
منهج واجراءات البحث:

منهج البحث:

نظرا لطبيعة البحث الحالي تم استخدام المنهج الوصفي؛ بغرض جمع البيانات وتفسيرها، حيث يهدف المنهج الوصفي الي وصف ماهو كائن من ظواهر أو أحداث بعد جمع البيانات، كما يهدف الي تفسير الظواهر

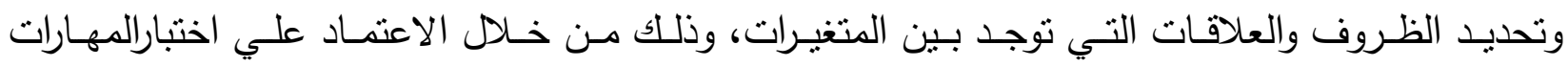
الاجتماعيـة لاطفـال الروضـة، ومقيـاس تقبـل طفـل الروضـة للاخـر كـأداة لتعـرف العلاقـة بـين المهارات الاجتماعية وتقبل طفل الروضة للاخر •

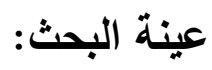
تكونت العينة من . 1 طفلا من المستوي الثاني برياض الاطفال •ه اناث ، . . ذكور من رياض أطفال مدرسة قليوب الرسمية للغات التابعة لادارة قليوب التعليمية بمحافظة القليوبية.

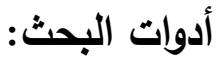

اسـتخدمت الباحثـة اختبـار المهــارات الاجتماعيـة لاطفــال الروضــة اعـداد ســهير كامـل، وبطــرس

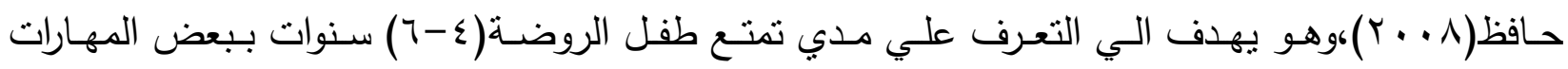
الاجتماعية التي يسلكها داخل او خارج المنزل، والتي يمكن من خلالها التعرف علي السلوك الذي يسلكه هـ من في منل سنه او مع من هم أكبر منهم أو أصغر سنا.

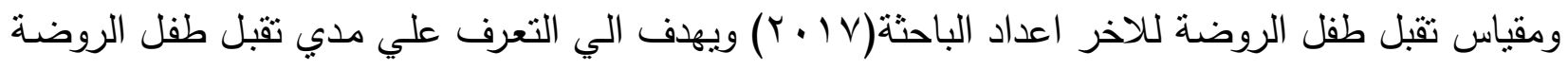
للاخر من خلال بعض المواقف المصورة واستجابة الاطفال عليها.

- أولا: مقياس تقبل طقل الروضـة للاخر: (إعداد الباحثة) قامت الباحثة بإعداد مقياس تقبل طفل الروضـة للاخر ، حيث قامت بالاطلاع على الدراسات السابقة والمقاييس والأطر النظرية، ؛ و قامت الباحثة بإعداد هذا المقياس بهدف قياس مدي تقبل طفل الروضة للاخر . 
1- الهذف من المقياس:

قياس مدي فهم الاطفال لابعاد مفهوم تقبل طفل الروضة للاخر وهي(تقبل الطفل للاخر المختلف، احترام رأي الاخر، التواصل الجيد مع الاخر، حديث الذات الايجابي عن الاخر، التوقع الايجابي عن الاخر).

الوصف العام للمقياس:

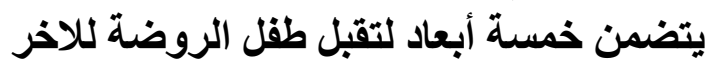

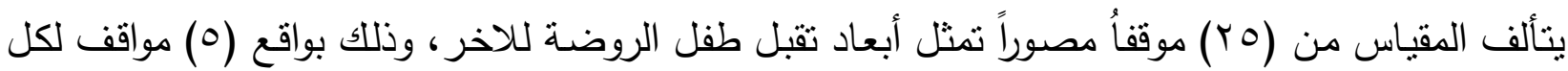

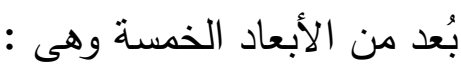

جدول (7)

توزيع أبعاد تقبل طقل الروضة للاخر في المقياس المصور

\begin{tabular}{|c|c|c|c|}
\hline أرقام المواقف فى المقياس & عدد المواقف & أبعاد المقياس & r \\
\hline $0-1$ & $\bullet$ & بُعد تقبل الطقل للاخر المختلف & 1 \\
\hline $1 \cdot-7$ & $\bullet$ & بُعد احترام الرأي الاخر & $r$ \\
\hline $10-11$ & $\bullet$ & بُعد التواصل الجيد مع الاخر & r \\
\hline$r \cdot-17$ & $\bullet$ & بُعد حديث الأت عن الاخر & $\varepsilon$ \\
\hline$r_{0}-r_{1}$ & ○ & بُعد التوقع الايجابي عن الاخر & - \\
\hline
\end{tabular}

تحديد المفاهيم الإجرائية لأبعاد مفهوم تقبل الاخر وذلك من خلال الإطار النظرى والدراسات

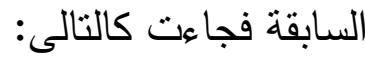

أولا:- تقبل الطقل للاخر المختلف وتعرفه الباحثه إجرائيـاً (هو مدى ادراك وتقبـل الطفل لغيره المختلف عنهـ في الجنس والعقبدة والطبقـة

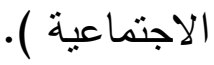
ثانياً:- احترام رأي الاخر وتعرفه الباحثه إجرائياً( ) هوتقدير الطفل للحوار مع الاخر) 


\section{ثالثاً:- التواصل الجيا مع الاخر}

وتعرفه الباحثه إجرائياً (هو اهتمام الطفل والتفاعل الايجابي مع الاخر) رابعاً:- حديث الذات الايجابي عن الاخر

وتعرفه الباحثه إجرائياً ( هو محاولة الطفل وقدرته علي استدعاء صور ايجابية عند حدوث مشكلة). خامساً: التوقع الايجابي عن الاخر وتعرفه الباحثه إجرائياً (هو قدرة الطفل علي التعبير عن قدرته علي تحقيق النجاح وتوقع الافضل أثناء تعامله مع الاخرين في المواقف المختلف . لمردئ

الخصائص السيكومترية لمقياس تقبل طقل الروضة للاخر المصور قامت الباحثة بايجاد معاملات الصدق و الثبات للأختبار وذلك على عينة قوامها . . اطفلا. معاملات الصدق الصدق العاملي: - n - n

قامت الباحثة بإجراء التحليل العاملي التحققى لبنود الأختبار حيث استخرجت معاملات الارتباط بين فقراته

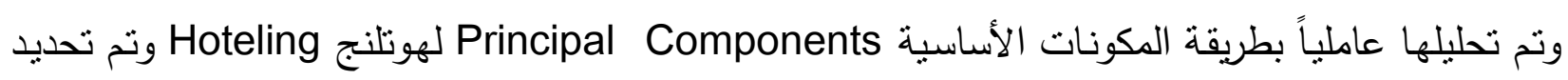
Kaiser بألا تقل عن واحد صحيح على محك كايزر

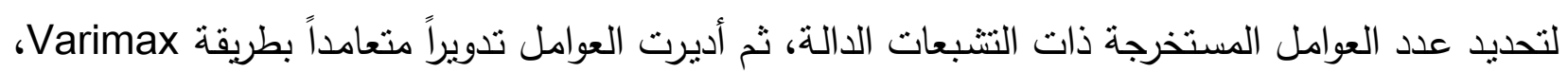
هذا وقد اعتبر محك النتبع الجوهري للعامل وفقاً لمحك جليفورد، والذي يكون ذو دلالة لا تقل عن • rا. • .و

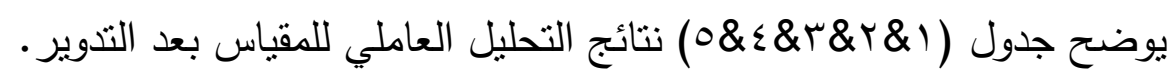




$$
\begin{aligned}
& \text { جدول ( } 1 \text { ) } \\
& \text { التشبعات الخاصة بالبعد الاول }
\end{aligned}
$$

\begin{tabular}{|c|c|c|}
\hline التشبعات & البنود & رقم العبارة \\
\hline$\cdot, \mathrm{v}$ & & 1 \\
\hline., 79 & & $r$ \\
\hline . & & $r$ \\
\hline . 10 & & $\xi$ \\
\hline$\cdot, \%$ & & 0 \\
\hline Y,YY & الجذز الكامن & \\
\hline
\end{tabular}

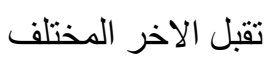

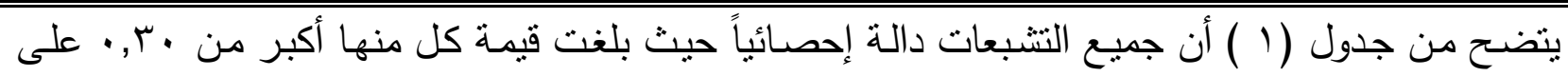

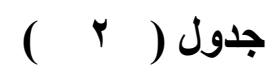

محك جيلفورد.

\begin{tabular}{|c|c|c|}
\hline التشبعات & البنود & رقم العبارة \\
\hline$\cdot, v$. & & 7 \\
\hline ס7, & & $v$ \\
\hline . $7 \leqslant$ & & $\Lambda$ \\
\hline צY & & 9 \\
\hline., 09 & & 1. \\
\hline$\overline{r, .0}$ & الجذر الكامن & \\
\hline
\end{tabular}

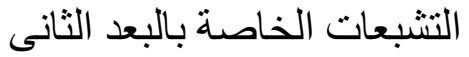

$$
\text { احتر ام رأي الاخدر }
$$

يتضح من جدول (r ) أن جميع التشبعات دالة إحصائياً حيث بلغت قيمة كل منها أكبر من · r, · على محك جيلفورد.

\begin{tabular}{|c|c|c|}
\hline التشبعات & البنود & رقم العبارة \\
\hline דו7, & & 11 \\
\hline$\cdot, 71$ & & Ir \\
\hline$\cdot, 0 \wedge$ & & ir \\
\hline$\cdot, 00$ & & $1 \varepsilon$ \\
\hline$\cdot, \leqslant 4$ & & 10 \\
\hline 1,70 & الجذر الكامن & \\
\hline
\end{tabular}

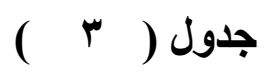

التشبعات الخاصة بالبعد الثالث

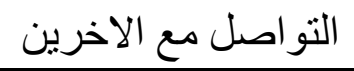

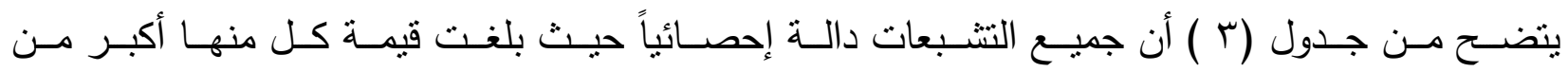




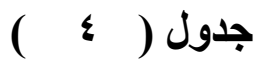 \\ التثبعات الخاصة بالبعد الر ابع الابع \\ حديث الذات الايجابي مع الاخر النابع}

\begin{tabular}{|c|c|c|}
\hline التشبعات & البنود البنو & رقم العبارة \\
\hline$\cdot, 09$ & & 17 \\
\hline$\cdot, 0 \wedge$ & & IV \\
\hline$\cdot, \infty 0$ & & 11 \\
\hline .,OY & & 19 \\
\hline$\cdot, \varepsilon \wedge$ & & $r$. \\
\hline $1, \varepsilon \wedge$ & الجذر الكامن & \\
\hline
\end{tabular}

يتضـح مـن جـدول (ع ) أن جميـع التشـبعات دالـة إحصـائياً حيـث بلغـت قيمـة كـل منهـا أكبـر مـن

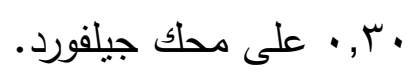

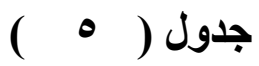

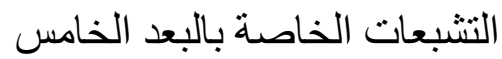

التوقع الايجابي تجاه الاخر

\begin{tabular}{|c|c|c|}
\hline التشبعات & البنود & رقم العبارة \\
\hline., 00 & & $r 1$ \\
\hline$\cdot, \leqslant \Lambda$ & & $r r$ \\
\hline$\cdot, \leqslant 7$ & & $r r$ \\
\hline$\cdot, \leqslant 0$ & & $Y \leq$ \\
\hline$\cdot, \sum Y$ & & ro \\
\hline 1,14 & الجذر الكامن & \\
\hline
\end{tabular}

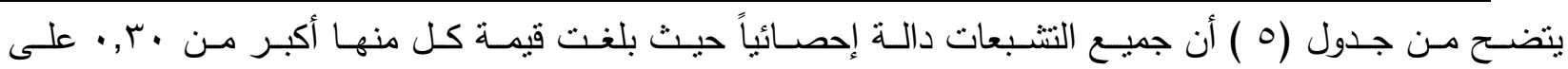

محك جيلفورد.

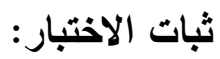

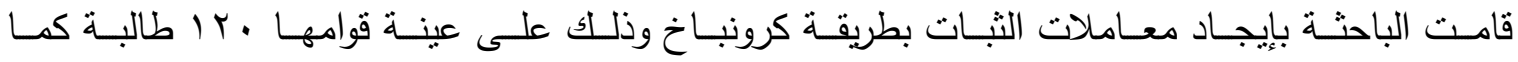

يتضح فى جدول (7) 


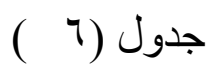

معامل الثبات لمقياس قبول الاخر المصور للاطفال

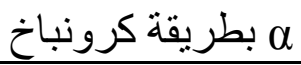

\begin{tabular}{|c|c|}
\hline 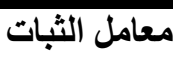 & المتغيرات \\
\hline$\cdot, \wedge \wedge$ & تقبل الاخر المختلف \\
\hline$\cdot, \wedge \varepsilon$ & احترام رأي الاخر \\
\hline$\cdot, \wedge \mathrm{T}$ & التواصل مع الاخرين \\
\hline$\cdot, \Lambda \mathrm{V}$ & حليث الذات الايجابي مع الاخر \\
\hline$\cdot, \wedge \Lambda$ & التوقع الايجابي تجاه الاخز \\
\hline$\cdot, \wedge q$ & اللارجة الكلية \\
\hline
\end{tabular}

يتضح من جدول (T)ارتفاع قيم معاملات الثبات م مما يدل على ثبات الاختبار . ثانيا: أختبار المهارات الاجتماعية لاطفال الروضة اعداد(سهير كامل،بطرس حافظ: ^ . . ؟) الهزف من الاختبار : قياس مدي فهم الاطفال لابعاد مفهوم المهارات الاجتماعية لاطفال الروضة (التواصل مع الاخرين، التفاعل الاجتماعي، المشاركة، السلوك الاجتماعي، التعبير الانفعالي، التعامل مع البيئة المدرسية). وصف الاختبار: يتكون الاختبار من ( • ؟)عبارة موزعة علي (7) أبعاد كما يتضح من الجدول التالي

مكونات اختبار المهارات الاجتماعية لطقل الروضة

\begin{tabular}{|c|c|c|}
\hline العبارات & 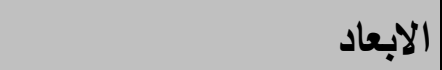 & م \\
\hline $16 V_{6} 1 r_{6} 1 q_{6} r \theta_{6} r I_{6} r V_{6} \leqslant r_{6} \leqslant q_{6} 00$ & التواصل مع الاخرين & 1 \\
\hline 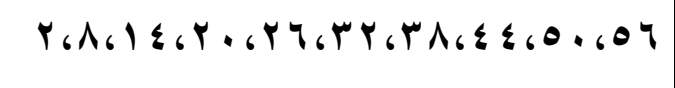 & التفاعل الاجتماعي & r \\
\hline$r 69,1 \theta_{6} r I_{6}, r V 6 r r 6 r q_{6} \leqslant \theta_{6} \theta 16 V \theta$ & المشاركة & $r$ \\
\hline 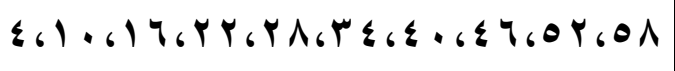 & السلوك الاجتماعي & $\varepsilon$ \\
\hline$\theta_{6}\left(1,6 V_{6} r r_{6} r q_{6} r \theta_{6} \& I_{6} \leqslant V_{6} \theta r_{6} \theta q\right.$ & التعبير الانفعالي & 0 \\
\hline 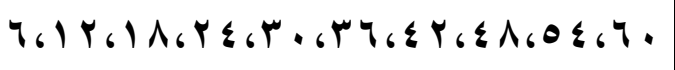 & التعامل مع البيئة المدرسية & 7 \\
\hline
\end{tabular}

الخصائص السبكومتريةلاختبار المهارات الاجتماعية

قامت الباحثة بايجاد معاملات الصدق و الثبات للأختبار وذلك على عينة قوامها ـ . . اطفلا. 
معاملات الصدق

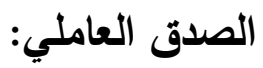
قامـت الباحثـة بـإجراء التحليـل العـاملي التحققى لبـــود الأختبـار حيـث اسـتخرجت معـاملات الارتبـاط بـين فقراتـه وتـم تحليلهـا عامليـاً بطريقـة المكونـات الأساسـية Principal Components لهـوتلنج

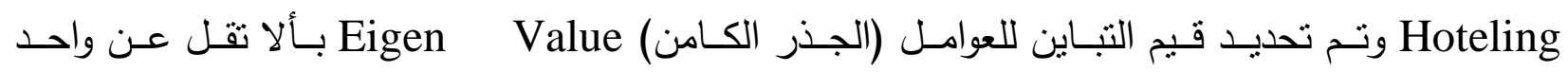

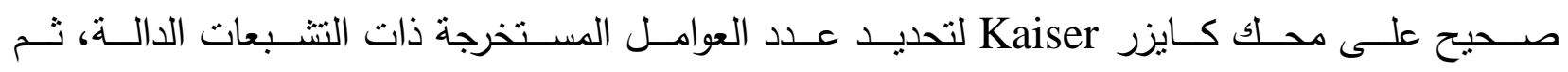

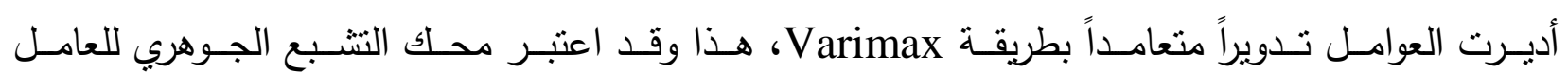

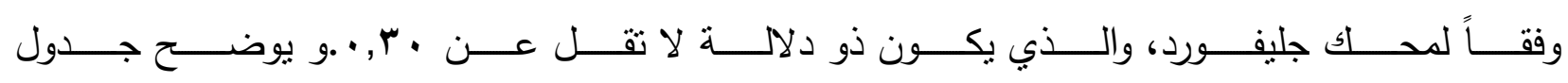
• نتائج التحليل العاملي للمقياس بعد التدوير ( ) \& \& \& \& \& \& \&V)

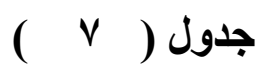

التشبعات الخاصة بالبعد الاول

التو اصل مع الاخرين

\begin{tabular}{|c|c|c|}
\hline التشبعات & البنود & رقم العبارة \\
\hline •, Тะ & & 1 \\
\hline Tוז, & & r \\
\hline צו, & & $r$ \\
\hline$\cdot, 7$ & & $\varepsilon$ \\
\hline$\cdot, 7$ & & 0 \\
\hline$\cdot, 4$ & & 7 \\
\hline., 09 & & $\mathrm{v}$ \\
\hline., 09 & & $\Lambda$ \\
\hline$\cdot, 0 \mathrm{~V}$ & & 9 \\
\hline., 07 & & 1. \\
\hline$r, .4$ & الجذر الكامن & \\
\hline
\end{tabular}

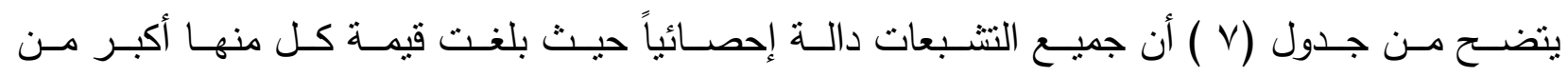
. آ • • على محك جيلفورد. 


\section{جدول ( 1 ) \\ التشبعات الخاصة بالبعد الثانى \\ التفاعل الاجتماعي}

\begin{tabular}{|c|c|c|}
\hline التثبعات & البنود & رقم العبارة \\
\hline., 7 & & 11 \\
\hline., 09 & & IY \\
\hline., 01 & & 14 \\
\hline., 07 & & $1 \leq$ \\
\hline$\cdot, 00$ & & 10 \\
\hline .,OY & & 17 \\
\hline., 01 & & IV \\
\hline$\cdot, \leqslant 9$ & & 11 \\
\hline$\cdot, \leqslant 0$ & & 19 \\
\hline . & & r. \\
\hline$r, \wedge r$ & الجذر الكامن & \\
\hline
\end{tabular}

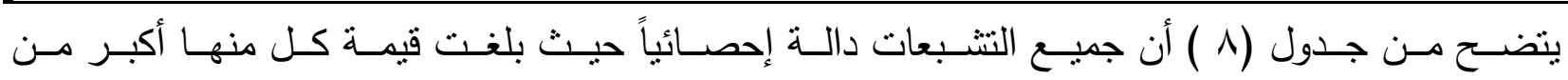
. آ • • على محك جيلفورد.

\section{جدول ( 9 ( )}

التشبعات الخاصة بالبعد الثالث

المشاركة بالمة

\begin{tabular}{|c|c|c|}
\hline التشبعات & البنود & رقم العبارة \\
\hline ., Or & & $\overline{Y T}$ \\
\hline., 01 & & TY \\
\hline., 0 & & YT \\
\hline$\cdot, \leqslant 0$ & & $r \varepsilon$ \\
\hline . & & ro \\
\hline$\cdot, \varepsilon Y$ & & Yq \\
\hline . & & $r V$ \\
\hline e, & & $r \wedge$ \\
\hline . & & rq \\
\hline • , I & & $r$. \\
\hline $1, \mathrm{VV}$ & الجذر الكامن & \\
\hline
\end{tabular}

يتضـح مـن جـدول (9 ) أن جميـع التشـبعات دالـة إحصـائياً حيـث بلغـت قيمـة كـل منهـا أكبـر مـن

• r, • على محك جيلفورد. 


\section{جدول ( 1 ) )

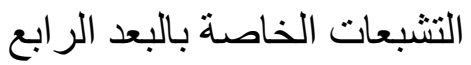 \\ السلوك الاجتماعي}

\begin{tabular}{|c|c|c|}
\hline التشبعات & البنود & رقم العبارة \\
\hline • & & $\mu_{1}$ \\
\hline$\cdot$, & & Tr \\
\hline - & & $r \mu$ \\
\hline 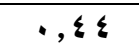 & & $r \leqslant$ \\
\hline •, & & ro \\
\hline$\cdot, \varepsilon \pi$ & & T4 \\
\hline 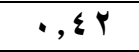 & & $r v$ \\
\hline$\cdot, \Gamma \mathrm{V}$ & & $r \Lambda$ \\
\hline ד ד & & rq \\
\hline . & & $\varepsilon$. \\
\hline $1, v_{0}$ & الجذر الكامن & \\
\hline
\end{tabular}

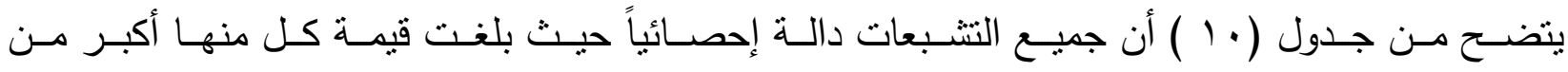
• r, • على محك جيلفورد.

\section{جدول ( 11 )}

التشبعات الخاصة بالبعد الخامس

التعبير الانفعالي باليخ

\begin{tabular}{|c|c|c|}
\hline التشبعات & البنود & رقم العبارة \\
\hline ., $\leqslant 0$ & & \$1 \\
\hline - & & $\varepsilon Y$ \\
\hline 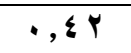 & & $\leqslant r$ \\
\hline$\cdot, \leqslant 1$ & & $\leqslant \varepsilon$ \\
\hline$\cdot, \leqslant 1$ & & $\leq 0$ \\
\hline$\cdot, \varepsilon$ & & $\leqslant 4$ \\
\hline$\cdot, \Gamma \leqslant$ & & $\varepsilon V$ \\
\hline 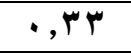 & & $\leqslant \wedge$ \\
\hline 更 & & $\leqslant 9$ \\
\hline$\cdot, \pi$ & & 0. \\
\hline $1, \leqslant 9$ & الجذر الكامن & \\
\hline
\end{tabular}

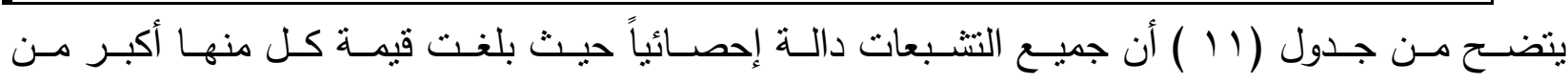

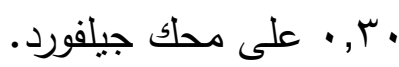




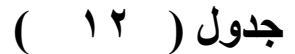

التشبعات الخاصة بالبعد السادس

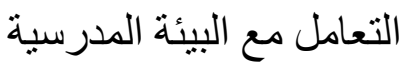

\begin{tabular}{|c|c|c|}
\hline التشبعات & البنود & رقم العبارة \\
\hline$\cdot, \xi$ & & 01 \\
\hline$\cdot, \pi q$ & & Or \\
\hline$\cdot, \Gamma \wedge$ & & or \\
\hline$\cdot, \Gamma \mathrm{V}$ & & $0 \leqslant$ \\
\hline$\cdot, \Gamma v$ & & 00 \\
\hline$\cdot, 44$ & & 07 \\
\hline$\cdot, \pi 4$ & & OV \\
\hline$\cdot ., 4$ & & $0 \wedge$ \\
\hline$\cdot$, ro & & 89 \\
\hline$\cdot$ & & 7. \\
\hline $1, r 0$ & الجذر الكامن & \\
\hline
\end{tabular}

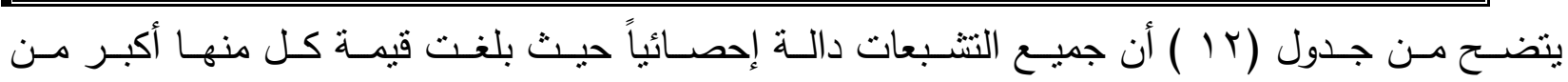
• آ, • على محك جيلفورد.

$$
\text { ثبات الاختبار: }
$$

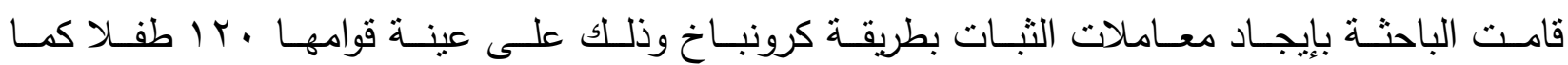

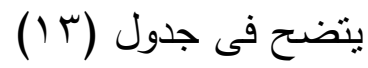

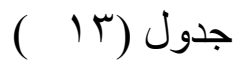

\begin{tabular}{|c|c|}
\hline معامل الثبات & المتغيرات \\
\hline$\cdot, 9$. & التواصل مع الاخرين \\
\hline$\cdot, 91$ & التفاعل الاجتماعي \\
\hline$\cdot, 9$ & المشاركةة \\
\hline$\cdot, \wedge q$ & السلوك الاجتماعي \\
\hline$\cdot, 9$. & التعبير الانفعالي \\
\hline$\cdot, \wedge \wedge$ & التعامل مع البيئة المدرسية \\
\hline., 9 & الارجة الكلية \\
\hline
\end{tabular}

معامل الثبات لمقياس المهارات الاجتماعية

يتضح من جدول (ب ا ))رتفاع قيم معاملات الثبات م مما يدل على ثبات الاختبار . 
نتائج البحث

القرض الاول

ينص الفرض الاول على انه : لا توجــ فـروق ذات دلالــة احصـائية فـي المهـارات الاجتماعيـة علـى مقيـاس المهـارات الاجتماعيـة لاي أطفال الروضة

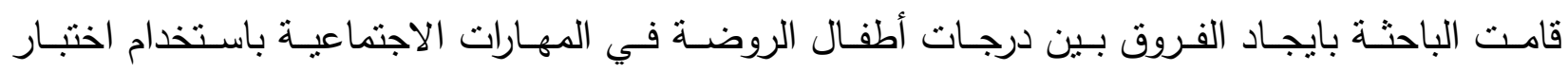
كاب كما يتضح فى جدول (ع ( ) جدول (ع () الفروق بين درجات أطفال الروضة في المهارات الاجتماعبة $0 .=\dot{0}$

\begin{tabular}{|c|c|c|c|c|}
\hline مستوى الدالة & كاץ & الانحراف المعيارى & | المتوسط & المتغيرات \\
\hline دالة عند مستوى 1 , , . & $r \varepsilon, \otimes V$ & $1, r$ & rr & التواصل مع الاخرين \\
\hline دالة عند مستوى 1 +,. & $r_{0, \varepsilon}$ & $1, r$ & $r r, \cdot r$ & التفاعل الاجتماعي \\
\hline |دالة عند مستوى 1 .,. & $r q, 1$ & 1,1 & $r \leqslant, \wedge$ & المشاركةة \\
\hline دالة عذد مستوى 1 +,. & $1 \cdot, r$ & $1, r$ & $r \cdot, r$ & السلوك الاجتماعي \\
\hline دالة عذ مستوى 1., . & $r v, \Lambda$ & 1,0 & YI,V & التعبير الانفعالي \\
\hline دالة عند مستوى 1 .,. & $r_{0,1}$ & 1,7 & $r \leqslant, \varepsilon$ & التعامل مع البيئة المدرسية \\
\hline غير دالة & 19,7 & \& & $1 r 0,9$ & الارجة الكلية \\
\hline
\end{tabular}

يتضح من جدول (ء () وجود فروق دالة احصائيا بين متوسطات رتب درجات الاطفال من حيث العمر

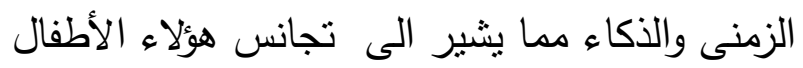
و يوضح شكل ( ) الفروق بين درجات أطفال الروضة في المهارات الاجتماعية 


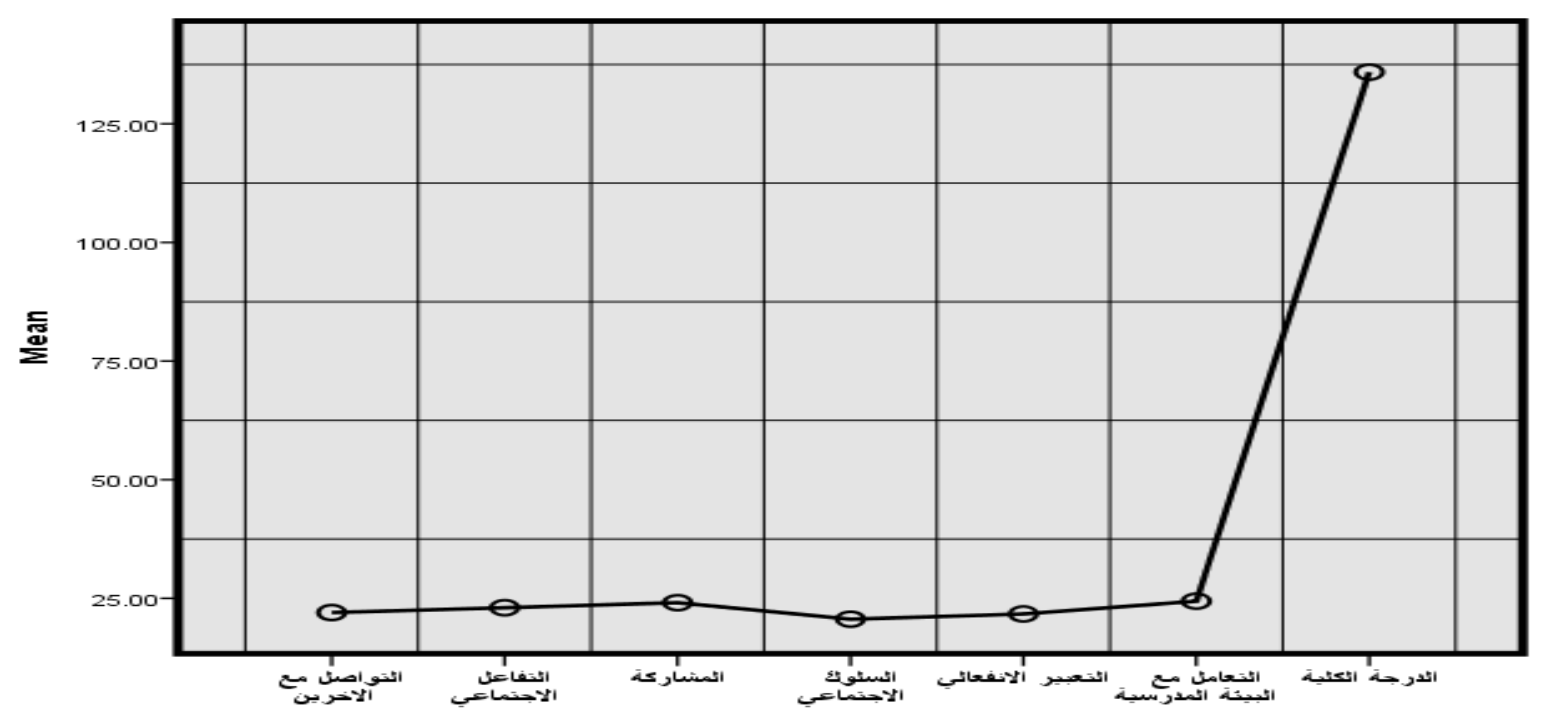

شكل (1)

الفروق بين درجات أطفال الروضة في المهارات الاجتماعية

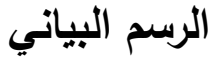

الفرض الثانى

ينص الفرض الثانى على انه :

لا توجد فروق ذات دلالة احصائية في التقبل للاخر على مقياس قبول الاخر المصور لاى طفل الروضة.

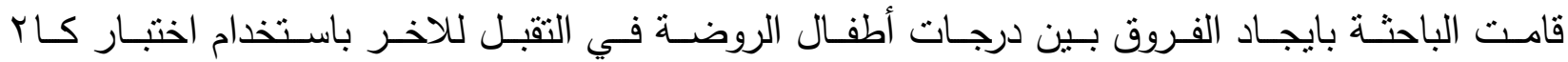
كما يتضح فى جدول (10)

$$
\text { جدول (10) }
$$

الفروق بين درجات أطفال الروضة في التقبل للاخر

○. $=$ ن

\begin{tabular}{|c|c|c|c|c|}
\hline مستوى الدلالة & كاץ & الانحراف المعيارى & المتوسط & المتغيرات \\
\hline دالة عذد مستوى ا .,. & $r \leqslant, \varepsilon$ & 1,1 & $\Lambda, \mathrm{V}$ & تقبل الاخر المختلف \\
\hline دالة عند مستوى 1 .,. & $r r, r$ & $1, r$ & $\Lambda, \mathrm{V}$ & احترام رأي الاخر \\
\hline دالة عند مستوى 1 .,. & $r \cdot, .0$ & $1, r$ & $\Lambda, r$ & التواصل مع الاخرين \\
\hline دالة عند مستوى 1 ., . & $r \leqslant, r$ & 1 & $\Lambda, r$ & الاخرث الذات الايجابي مع \\
\hline دالة عند مستوى | .,. & $r v, r$ & 1,7 & $9, \varepsilon$ & التوقع الايجابي تجاه الاخر \\
\hline دالة عذد مستوى | ., . & $r \Lambda, 0$ & $9, v$ & $\{\mu, 0$ & الارجة الكلية \\
\hline
\end{tabular}

يتضح من جدول (10) وجود فروق دالة احصائيا عذ مستوى 1., · بين درجات أطفال الروضة في التقبل للاخر 


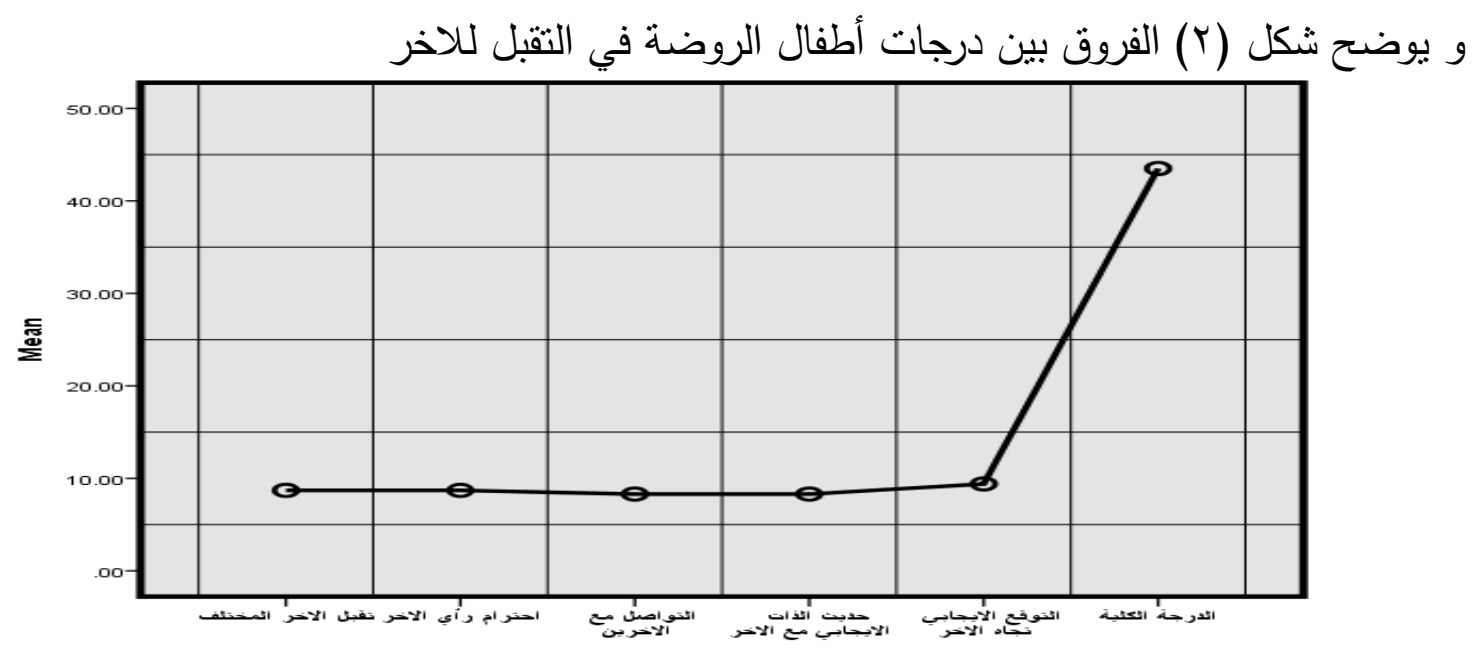

شكل (r)

الفروق بين درجات أطفال الروضة في التقبل للاخر

الفرض الثالث

ينص الفرض الثالث على انه :

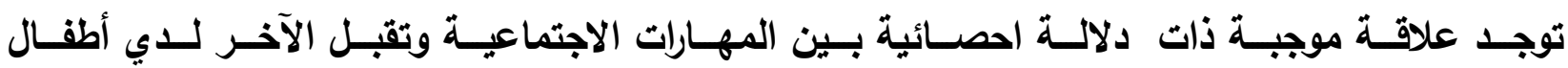
الروضة - - الرجة قامـت الباحثـة بايجـاد العلاقـة بـين المهارات الاجتماعيـة وتقبـل الآخـر لـــي أطفـال الروضــة باسـتخدام

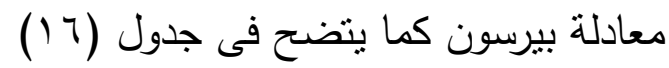

جدول (17)

العلاقة بين المهارات الاجتماعية وتقبل الآخر لدي أطفال الروضة باستخدام معادلة بيرسون

$$
0 \text {. }=0
$$

\begin{tabular}{|c|c|c|c|c|c|c|}
\hline الألرجة الكلية & الايجابي تجاه & الايجابي مع الذات & الاخرين & احترام رأي & تقبّل الاخفر & المتغيرات \\
\hline$\cdot, 1 \leqslant$ & $\cdot, .99$ & $* *$, , & $\cdot, 1$. & $\cdot, \cdot . \mathrm{V}$ &., .4 & التواصل مع الاخرين \\
\hline$\cdot, \cdot r$ & $\cdot, \cdot \wedge$ & $\cdot, \cdot \mathrm{V}$ & • & $\cdot, 1 \mu$ &.,.$r$ & التفاعل الاجتماعي \\
\hline$\cdot, \cdot r$ & $\cdot, \cdot r$ & $\cdot, 1 \leqslant$ & $\cdot, ., \xi$ & $\cdot, ., 9$ & $\cdot, ., 0$ & المشاركة \\
\hline$\cdot, ., 1$ & $\cdot, ., 0$ & •, Yo & $\cdot, ., 1$ & •, YY & $\cdot, \mathrm{IV}$ & السلوك الاجتماعي \\
\hline$\because, r \leq-$ & $* \cdot, \Gamma 1-$ & $\cdot, 1$. & $\cdot, 11$ & $\cdot, \cdot \mathrm{V}$ &., .4 & التعبير الانفعالي \\
\hline • & $\cdot, Y$ & $\cdot, 14$ & $\cdot, 1 \leqslant$ & $\cdot, \cdot, \varepsilon$ & $\cdot, \cdot \wedge$ & المدرسية مع البيئة \\
\hline$\cdot$, , & - YT & $\cdot, \cdot r$ & $\cdot, 14$ & $\cdot, 10$ & $\cdot, .99$ & الارجة الكلية \\
\hline
\end{tabular}




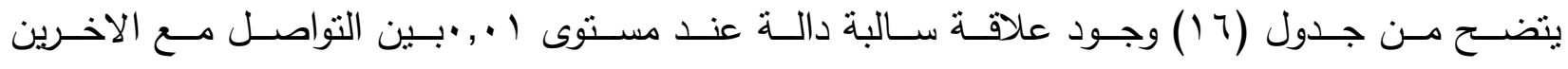

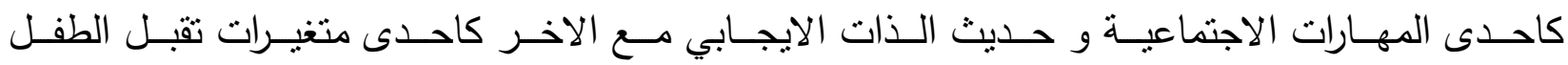
للآخر

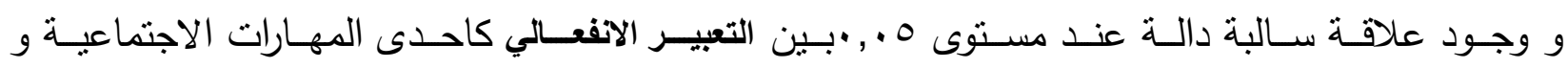

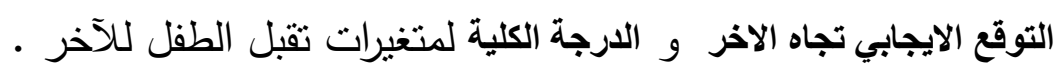
تفسير النتائج في ضوء الاراسات:

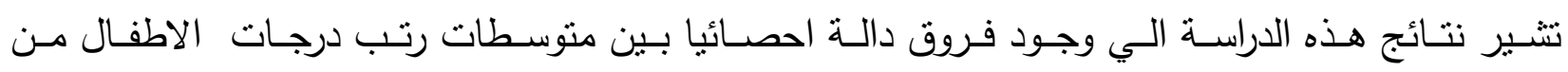
حيث العمر الزمنى والذكاء مما يشير الى تجده تجانس هؤلاء الأطفال.

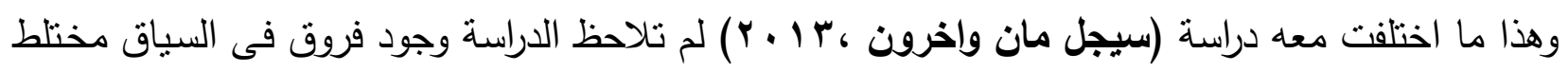

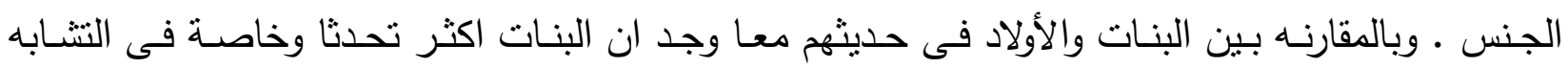

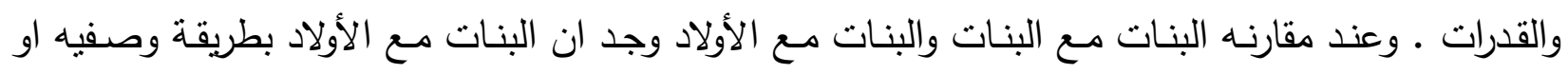

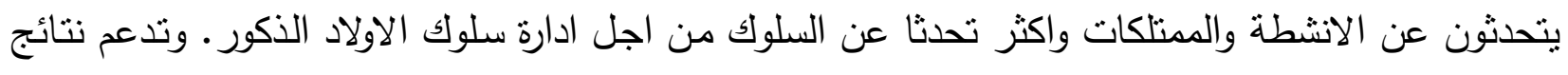
الدراسة المنظور الاجتماعى بنائى او السياقى وليس المنظور البيولوجى عن الفروق الجنسية بين الأطفال .

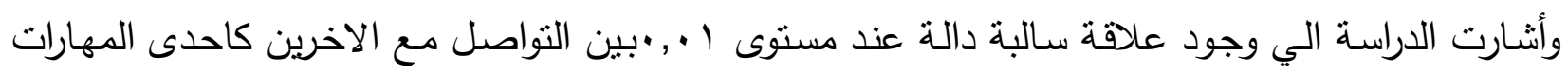

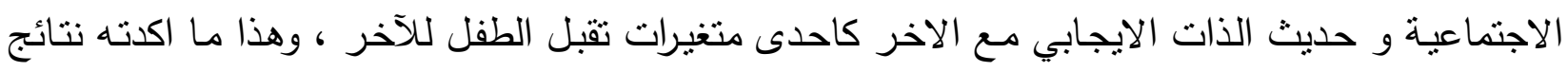

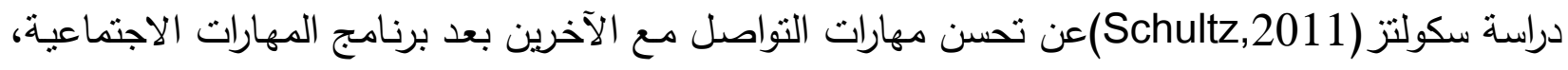
الكفاءة الانفعالية الاجتماعية بالتغيير الايجابي في سلوك الاطفال.

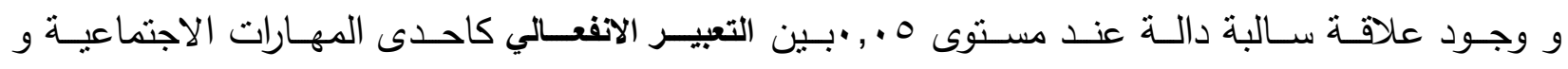

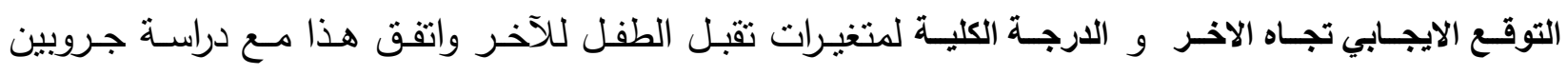

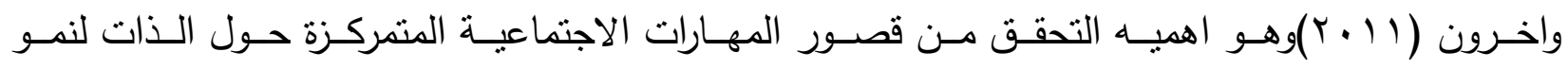

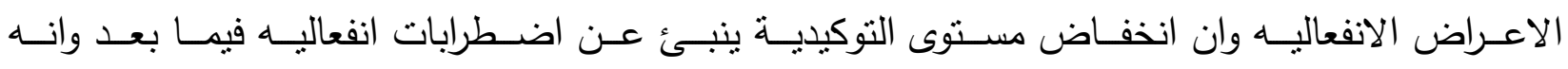

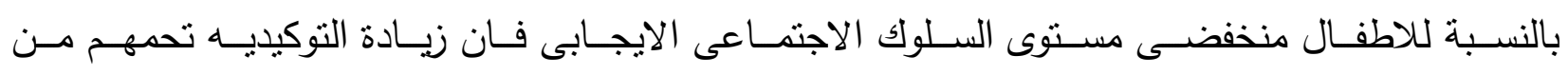

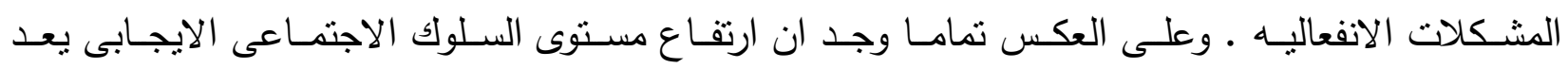

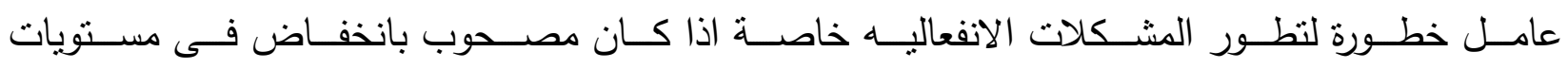
المشاركة الاجتماعية.

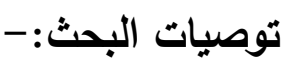

-اهمية اعداد وتقديم الدورات والبرامج التنريبية لتتمية المهارات الاجتماعية للاطفال. -تقديم البرامج الارشادية للاطفال عن تقبل الاخر . 


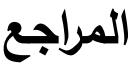

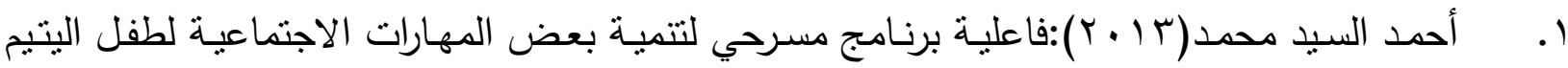

بمؤسسات الرعاية الاجتماعية-دراسة تجريبية،مجلة كلية التربية،عدد بو، مجلد ؟ ك، جامعة بنها.

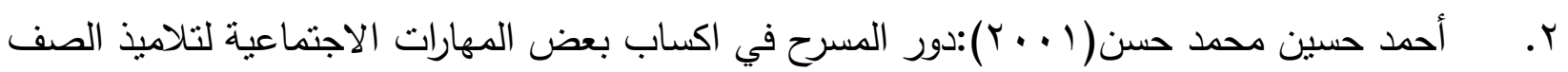
الرابع الابتدائي،رسالة ماجستير غير منشورة،معهد الدراسات العليا للطفولة، جامعة عين شمس.

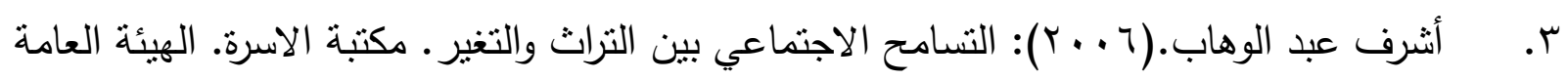

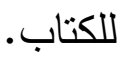

ع. أمل محمد حسونة(990 (1)): تصميم برنـامج لاكساب أطفال الرياض بعض المهارات الاجتماعية،

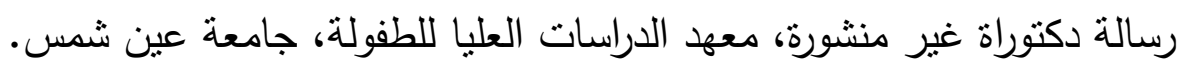

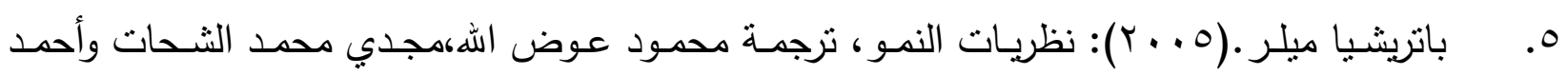
عاشور • عمان. دار الفكر . بان.

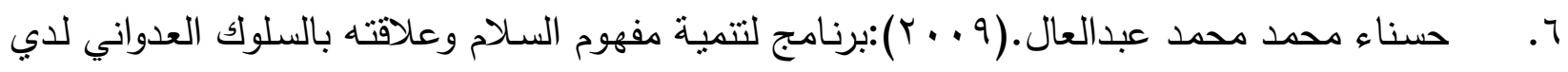
طفل الروضة. رسالة ماجستير • قسم العلوم النفسية. كلية رياض الاطفال. جامعة القاهرة.

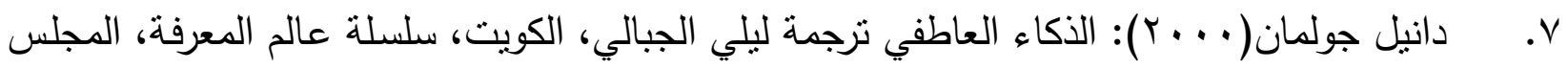
الوطني للنقافة والفنون والاداب. ^. زينب علي محمد(7 ( • ب):ثقافة قبول الآخر لدي الطالبة/المعلمـة بكلية رياض الاطفال-جامعـة

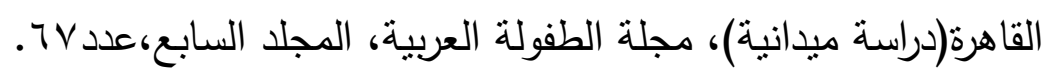

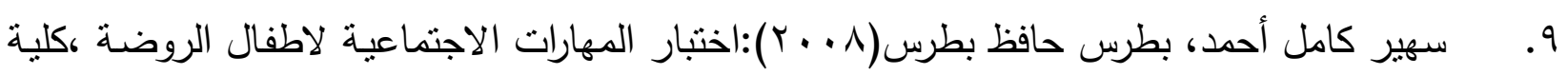
رياض الاطفال، جامعة القاهرة.

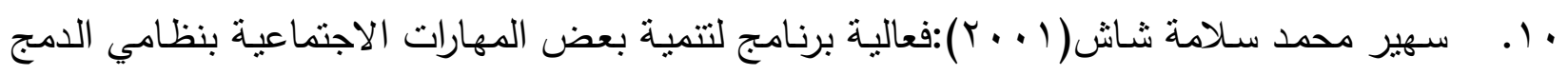

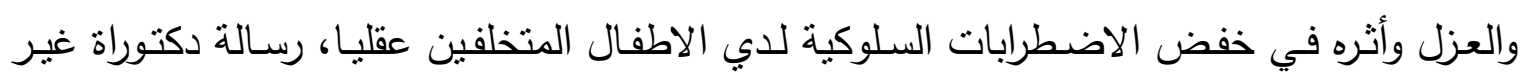
منشورة،كلية التربية، جامعة الزقزيق.

1) والاخر في التقافة العربية. مركز الدراسات الانسانية. والمستقبليات. كلية الاداب. جامعة عين شمس.

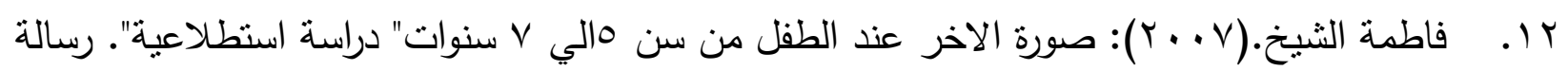
ماجستير • معهد الدراسات العليا للطفولة. جامعة عين شمس. $\Lambda \vee V$ 


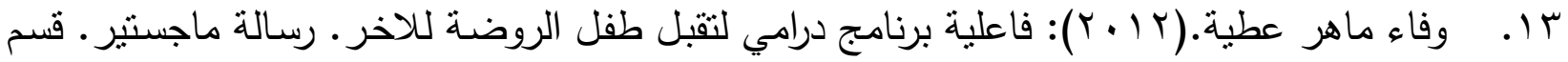
العلوم الاساسية. كلية رياض الاطفال. جامعة القاهرة.

14. Grizenko, N., Zappitelli, M., Langevin, J., Hrychko, S., El-Messidi, A., Kam in ester, D., \& Stepanian, M. (2000). Effectiveness of a social skills training

15. Grizenko, N., Zappitelli, M., Langevin, J., Hrychko, S., El-Messidi, A., Kam in ester, D., \& Stepanian, M. (2000). Effectiveness of a social skills training

16. -Groeben, M., Perren, S., Stadelmann, S., \& Klitzing, K. (2011). Emotional symptoms from kindergarten to middle childhood: associations with self- and other-oriented social skills. European Child \& Adolescent Psychiatry, 20(1), 3-15. doi:10.1007/s00787-010-0139-Z

17. -Kim, S., Sodian, B., \& Paulus, M. (2014). 'Does he need help or can he help himself?' Preschool children's expectations about others' instrumental helping versus self-helping. Frontiers In Psychology, 5

18. Kim, S., Sodian, B., \& Paulus, M. (2014). 'Does he need help or can he help himself?' Preschool children's expectations about others' instrumental helping versus self-helping. Frontiers In Psychology,

19. Schultz, B., Richardson, R., Barber, C., \& Wilcox, D. (2011). A Preschool Pilot Study of Connecting with Others: Lessons for Teaching Social and Emotional Competence. Early Childhood Education Journal, 39(2), 143-148.

20. Schultz, B., Richardson, R., Barber, C., \& Wilcox, D. (2011). A Preschool Pilot Study of Connecting with Others: Lessons for Teaching Social and Emotional Competence. Early Childhood Education Journal, 39(2), 143-148.

21. Sigelman, C. K., \& Holtz, K. D. (2013). Gender differences in preschool children's commentary on self and other. The Journal Of Genetic Psychology: Research And Theory On Human Development, 174(2), 192-206. doi:10.1080/00221325.2012.662540 